\title{
Production of Activated Carbon from Carbonaceous Agricultural Waste Material: Coconut Fibres
}

\author{
E. O. Ohimor ${ }^{\mathrm{a}, *}$, D. O. Temisa ${ }^{\mathrm{a}}$, P. I. Ononiwu ${ }^{\mathrm{b}}$ \\ ${ }^{a}$ Department of Chemical Engineering, Federal University of Petroleum Resources, Delta State, NIGERIA. \\ ${ }^{b}$ Production Chemicals and Laboratory Service Division, Darew Ventures Limited, Delta State, NIGERIA.
}

\begin{abstract}
Activated carbon was produced from Cocos nucifera (coconut) fibers by carbonization and activation processes. The sample was first pretreated before carbonization and activation processes at $450^{\circ} \mathrm{C}$ and $700^{\circ} \mathrm{C}$ respectively in an electric furnace. Chemical activation using Potassium hydroxide (KOH) 4:1 (weight basis) was carried out to increase the activated carbon adsorption properties. The element contained in the sample was analyzed using the Energy Dispersive Spectroscopy (EDS) while the surface morphological composition was determined by Scanning Electron Microscope (SEM) and the chemical bonds present in the sample was characterized using Fourier transform infrared reflection (FT-IR). From the research carried out, the results show that activated carbon produced from coconut fibers would be useful and effective for adsorbent purposes, considering its large pores.
\end{abstract}

Keywords: activated carbon, adsorbent, adsorption, coconut fibers

\section{INTRODUCTION}

Coconut is widely cultivated and consumed in many parts of the world. The non-edible parts of the coconut, which is the shell and fibre, constitute a nuisance to the environment. The waste coconut fibers, though biodegradable over a very long period, can cause health challenges through serving as breeding grounds for pests, rodents, and pathogenic organisms, when indiscriminately dumped. It can also pose health challenges, resulting from air pollution when incinerated.

In recent years, activated carbon is very common among researchers because they are focusing on recycling solid carbonaceous agricultural waste into useful products and this is aimed at reducing the impact of waste on the environment. Activated carbon is popularly gotten from solid carbonaceous materials such as rice hulls, rice straw, coffee husk, beans curd refuse, sugarcane bagasse, coconut fibers/shell, eggshell etc. [1-7].

Activated carbon is a porous carbonaceous material prepared through the carbonization and activation of organic substances, especially of plant source. Significantly, agricultural waste materials mostly of plant origin contain cellulose, lignin, ash and other organic compounds. The carbonization process is needed in order to decompose the organic compounds into activated carbon [8]. During carbonization of raw lignocellulosic material,

\footnotetext{
* Corresponding author (Tel: +234 (0)803 388 8418)

Email addresses: ohimor.evuensiri@fupre.edu.ng (E. O. Ohimor), divinetemisa@gmail.com (D. O. Temisa), prince3iyke75@gmail.com (P. I. Ononiwu)
}

a solid residue (charcoal) and volatile gases are produced [9]. During this process pores, i.e., voids between the graphite crystals, are formed. Activation occurs immediately and may be chemical or physical. The intermediate product is removed, and the graphite crystals become exposed to the activating agent [10]. This increases the number and the dimensions of the pores during activation.

As such, rather than indiscriminate disposal or incineration, turning the waste to a useful product becomes a better option. One of such possibilities is the idea of converting the waste coconut fibers to activated carbon which can be used for many industrial purposes. Furthermore, this concept would allow the agricultural byproducts which do not have any economic value to be commercialized into a new high value product [11]. This has lent credence to the campaign and idea of waste conversion/recycling, otherwise referred to as "waste to wealth".

\section{MATERIALS AND METHODS}

\subsection{Sample Collection}

For this research work, samples of fresh and dry Coconut (Cocus nucifera) fibers were gotten from waste site in Orerokpe Modern Market in Okpe Local Government Area of Delta State, Nigeria.

\subsection{Preparation of the Activated Carbon}

2.2.1. Pretreatment of the Coconut Fiber Samples

The samples of coconut fibers were washed with deionized water and sun dried for about three weeks to remove moisture and then the sample size was chopped into smaller sizes of different irregular shapes to ease arrangement and placement in the crucible before carbonization. 


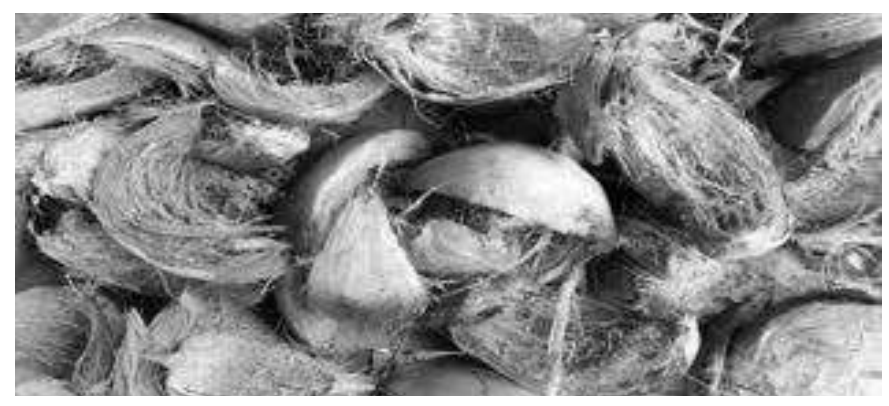

(a) Sample of fresh coconut fibres

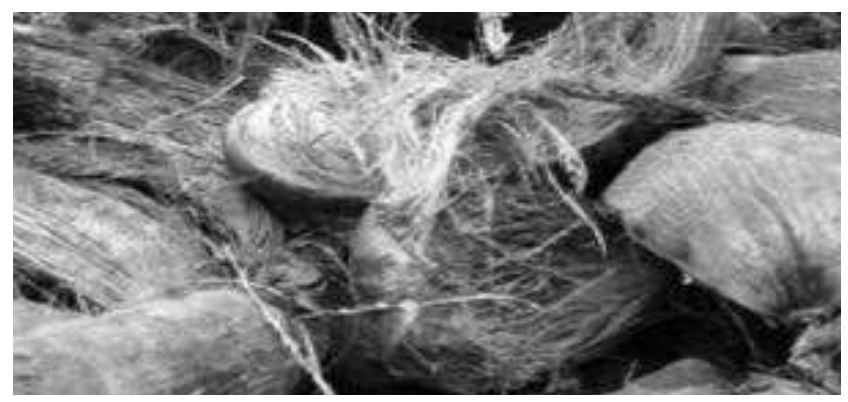

(b) Samples of dry coconut fibres

Figure 1: Samples of fresh and coconut fibres.

\subsubsection{Carbonization, Impregnation and Activa- tion of the Samples}

The prepared sample $(3.0 \mathrm{~kg}$ wt. \% of coconut fibers) in a crucible were subjected to thermal decomposition in batches using electric furnace at a temperature of $450^{\circ} \mathrm{C}$ for 30 minutes and the samples were brought out, sprinkled with deionized water to stop continuous burning of the carbonized coconut fibers and then allowed to cool off till the following day. The carbonized coconut fibers (about 22 wt. \% of the initial were recovered after carbonization) were impregnated using $\mathrm{KOH} 1.5 \mathrm{M}$ (4:1, weight basis) for about 24 hours before chemical activation using electric furnace at a temperature of $700^{\circ} \mathrm{C}$, maintaining $10^{\circ} \mathrm{C} / \mathrm{min}$ heating rate for 150 minutes. After activation, the samples were washed with deionized water several times to remove the alkaline content impacted into it by the $\mathrm{KOH}$ while the $\mathrm{pH}$ was checked till it becomes neutral using litmus paper and the adsorbent was dried using electric oven at $120^{\circ} \mathrm{C}$ for about 60 minutes. The size of the dried adsorbent was reduced using mortar and pestle to desired sizes before sieving in a separate container.

\subsection{Characterization of the Activated Car- bon Produced}

\subsubsection{Determination of $p H$}

The activated carbon of $1.0 \mathrm{~g}$ was dissolved in $20 \mathrm{ml}$ of distilled water. The mixture was heated and agitated in a water bath at room temperature for 60 minutes to ensure proper dilution of the sample. The mixture was filtered and the $\mathrm{pH}$ of the clear filtrate was read using digital $\mathrm{pH}$ meter.

\subsubsection{Determination of pore volume}

The activated carbon sample of $1.0 \mathrm{~g}$ was added to $25 \mathrm{ml}$ of distilled water. The mixture was heated for about 15 minutes, drained and dried after which it was weighed. The pore volume was determined using Eq. (1):

$$
\text { Pore Volume }=\frac{W_{i}-W_{f}}{W_{i}} \times \mathrm{H}_{2} \mathrm{O} \text { Density }
$$

where $W_{f}$ is the final weight of sample $(\mathrm{g})$ and $W_{i}$ is the initial weight of sample $(\mathrm{g})$.

\subsubsection{Determination of percentage weight loss}

The sample was weighed before carbonization and the activation process, also reweighed after the final process. Thus, the percentage weight loss or weight decrease of the materials during preparation from the original weight of the raw material was calculated using the expression defined by Eq. (2):

$$
\begin{array}{r}
\text { Percentage of weight loss (\%) } \\
=\frac{L_{i}-L_{f}}{L_{i}} \times \mathrm{H}_{2} \mathrm{O} \text { Density }
\end{array}
$$

where $L_{i}$ is the initial weight of the material (coconut fibers before carbonization) and $L_{f}$ is the final weight of material (carbonized and activated sample).

\subsubsection{Determination of bulk density}

The activated carbon sample of $2 \mathrm{~g}$ was added to $5 \mathrm{ml}$ of distilled water in two separate measuring cylinders. The volume rise in the measuring cylinder was recorded and the bulk density of the sample was calculated using Eq. (3):

$$
=\frac{\text { Bulk density }\left(\mathrm{g} / \mathrm{cm}^{3}\right)}{\text { volume of water displaced by the sample }}
$$

\subsubsection{Determination of ash content}

The activated carbon sample of $3 \mathrm{~g}$ was placed in an empty crucible and the weight was measured and recorded. The crucible together with the sample was placed in a furnace and was heated from room temperature to $700^{\circ} \mathrm{C}$ and held at this temperature for 120 minutes before allowing it to cool to ambient temperature. The ash content was obtained using Eq. (4):

$$
\text { Ash content }=\frac{M_{a s h}-M_{c}}{M_{d s}-M_{c}}
$$

where $M_{c}$ is the mass of empty crucible (g), $M_{d s}$ is the mass of crucible plus dried sample (g) and $M_{a s h}$ is the mass of crucible plus ash sample (g). 

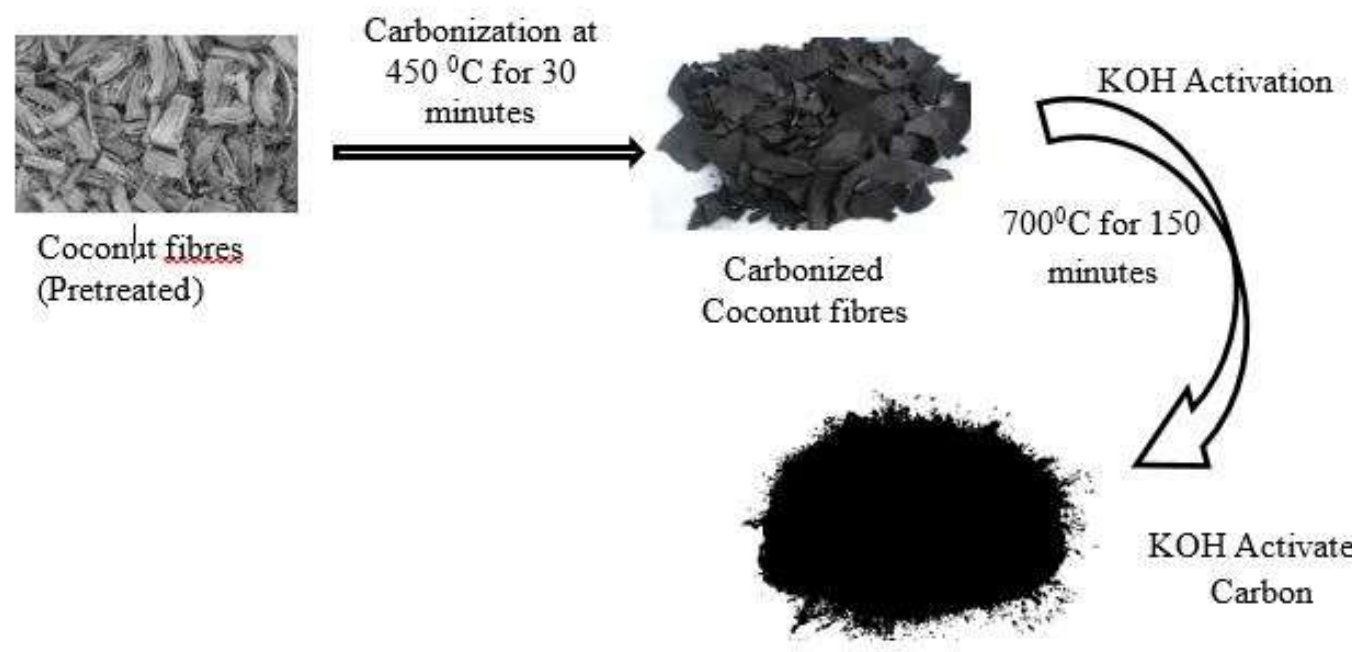

KOH Activated

Carbon

Figure 2: Diagram showing the production process of activated carbon from coconut fibres.

\subsubsection{Determination of moisture content $\left(X_{O}\right)$}

A dried clean empty crucible was weighed $\left(W_{1}\right)$. The activated carbon powder $3 \mathrm{~g}$ was placed into the crucible and was weighed $\left(W_{2}\right)$. The crucible containing the sampled powder was placed in an oven at $110^{\circ} \mathrm{C}$ while drying; the activated carbon was constantly reweighed at 10 minutes interval until the weight of the activated carbon became constant. The crucible plus the activated carbon was reweighed $\left(W_{3}\right)$. The weight loss of the activated carbon was used to determine the moisture content using the expression defined as.

$$
X_{O}=\frac{W_{2}-W_{3}}{W_{2}-W_{1}} \times 100
$$

where $W_{1}$ is the mass of empty crucible (g), $W_{2}$ is the mass of crucible plus sample before drying (g) and $W_{3}$ is the mass of crucible plus sample after drying (g).

\subsubsection{Determination of percentage yield}

The percentage yield of the precursor was calculated using the mathematical expression:

$$
\% \text { Yield }=\frac{Y_{i}-Y_{f}}{Y_{i}} \times 100
$$

where $Y_{i}$ is the initial weight of the precursor after drying and before carbonization and $Y_{f}$ is the final weight of the precursor after carbonization before activation.

\subsection{Fourier Transform Infrared Spectro- scope Analysis (FT-IR)}

The FT-IR analysis was carried out in order to determine the chemical composition, functional group and the type of bond present in the prepared adsorbent material. The adsorbent material was examined using Infrared Spectroscope (Transmittance method) in the range of 650$4000 \mathrm{~cm}^{-1}$ (wavelength).

\subsection{Scanning Electron Microscope (SEM) and Energy Dispersive Spectroscopy (EDS) Analyses}

In order to determine the surface morphological composition of the prepared adsorbent, the SEM analysis was carried out at magnifications $\mathrm{X}-1000$. While the elements present in the prepared adsorbent, was determined using the EDS magnifications X-500.

\section{RESULTS AND DISCUSSION}

\subsection{Carbonization and Activation of the Stalk Biomass}

Table 1: Results of Carbonization and activation.

\begin{tabular}{lc}
\hline Precursor & Coconut fibers \\
\hline Initial weight $(\mathrm{g})$ & 3200 \\
Weight after carbonization $(\mathrm{g})$ & 704 \\
\% Weight loss after carbonization & $78 \%$ \\
Weight of sample activated $(\mathrm{g})$ & 600 \\
Weight after activation $(\mathrm{g})$ & 570 \\
Percentage yield $(\%)$ & 21 \\
Carbonization temperature $\left({ }^{\circ} \mathrm{C}\right)$ & 450 \\
Activating agent & $\mathrm{KOH}$ \\
Activation temperature $\left({ }^{\circ} \mathrm{C}\right)$ & 700 \\
\hline
\end{tabular}

\subsection{Characterization of the Activated Car- bon}

The activated carbon considered in this work proved to be neutral. The acid or basic nature of an activated carbon depends on its preparation and the inorganic matter and chemically active oxygen groups on its surface as well as the kind of treatment to which the activated carbon was submitted $[9,12,13]$. 


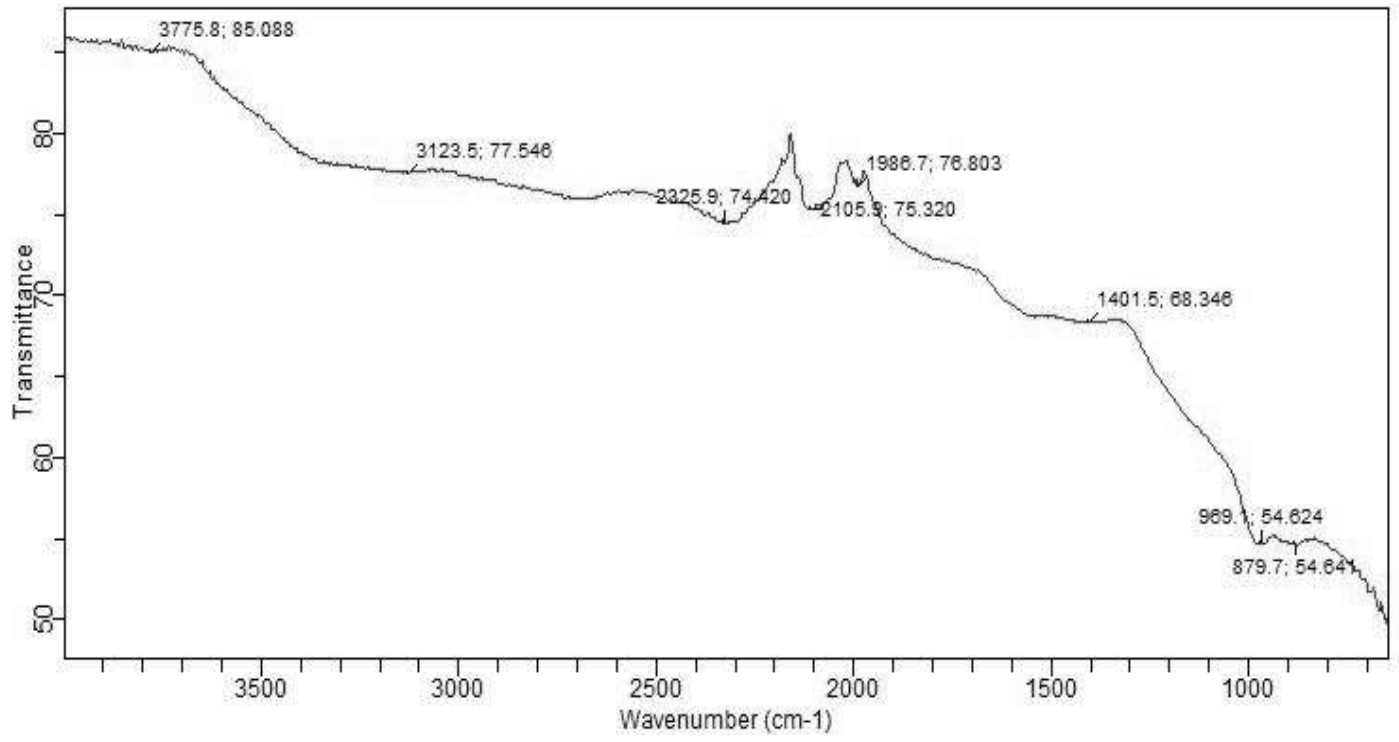

Figure 3: FT-IR Spectrum for coconut fibres.

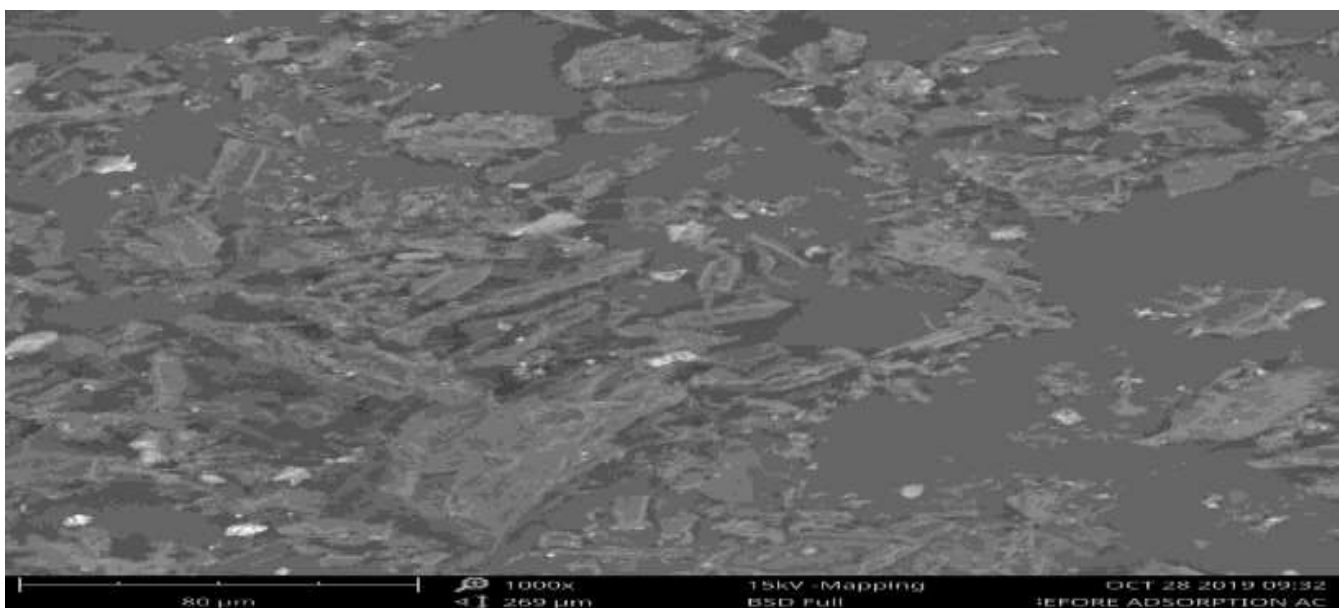

Figure 4: SEM Visualization of the microstructure of the coconut fibres at $\times 1000$ magnification.

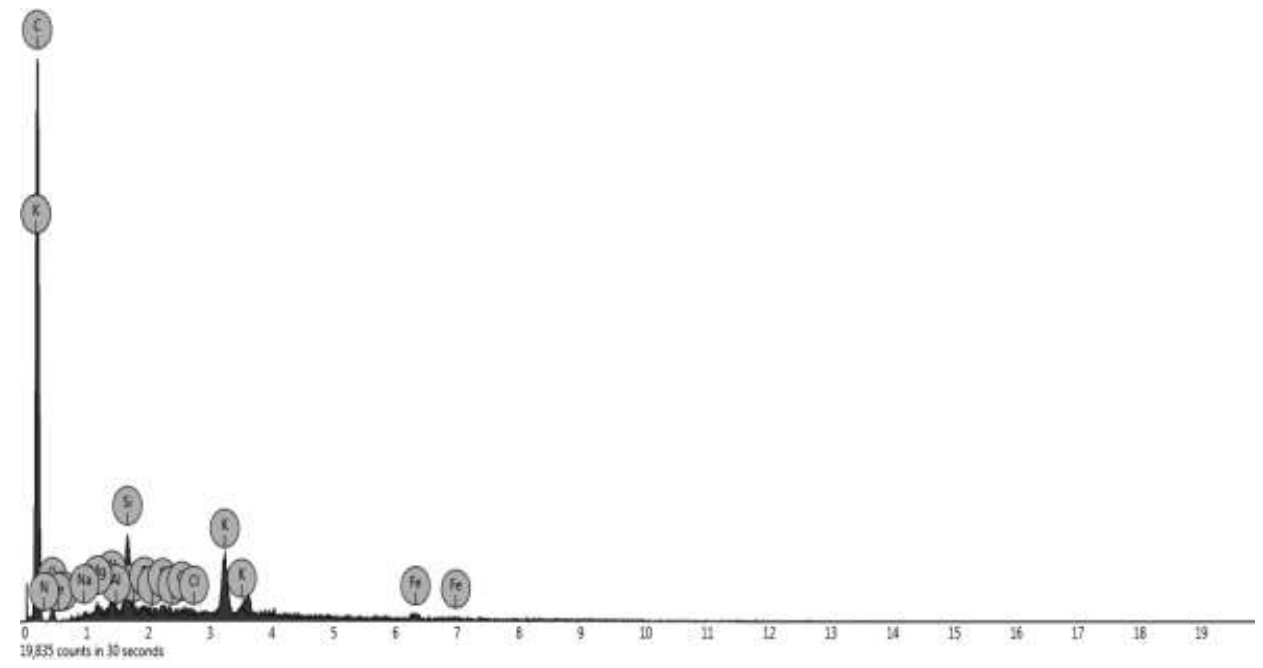

Figure 5: EDS Visualization of Elemental composition of the adsorbent at X-500 magnification. 
Table 2: Results of characterization of the activated carbon.

\begin{tabular}{lll}
\hline S/N & Parameter & Value \\
\hline 1 & pH & 7.03 \\
2 & Pore Volume & $0.78 \mathrm{E} 3$ \\
3 & Weight Loss $(\%)$ & 78 \\
4 & Bulk Density $\left(\mathrm{g} / \mathrm{cm}^{3}\right)$ & 0.16 \\
5 & Ash content $(\%)$ & 0.89 \\
6 & Moisture content $(\%)$ & 11.76 \\
7 & Colour & Black \\
8 & Particle size $(\mu \mathrm{m})$ & 63 \\
\hline
\end{tabular}

\subsection{FT-IR analysis}

The coconut fibers adsorbent, before it was used for adsorption experiment, shows the broad band $3775.8,3123.5,2325.9,2105.9,1986.7$ and $1401.5 \mathrm{~cm}^{-1}$ as shown in Fig. 3. At peak $3123.5 \mathrm{~cm}^{-1}, \mathrm{OH}$ acid (carboxylic acid) stretch was observed. Peak $2325.9 \mathrm{~cm}^{-1}$ shows the presence of the carbonate $\left(\mathrm{CO}_{2}\right)$ and peaks $2105.9,1986.7$ and $1401.5 \mathrm{~cm}^{-1}$ depicts the presence of an alkyne $(-\mathrm{C} \equiv \mathrm{C}-)$, transitional metals and an aromatic ($\mathrm{C}=\mathrm{C}-$ ) respectively [14].

From the FT-IR Spectrum for coconut fibers Fig. 3 , wavelengths corresponding to $400-1500 \mathrm{~cm}^{-1}$ are considered as fingerprint region. In this region, strong absorption intensity is usually observed [15]. The highest peak with frequency $\left(3123.5 \mathrm{~cm}^{-1}\right)$ suggests $\mathrm{OH}$ acid (carboxylic acid) is the main functional group present in the prepared adsorbent.

\subsection{SEM analysis}

The surface morphology of the prepared adsorbent shows a wide variety of pores, some shiny surface as spotted in the SEM figures (Fig. 4) at X-1000 magnification. This may be due to the reaction of the impregnating agent $(\mathrm{KOH})$. The particle sizes are irregular, containing high surface area available for adsorption of the adsorbate. Due to carbonization and activation, volatiles are removed producing a fixed carbon mass with widening of pore networks that are present in activated carbon sample. The presence of micropore contribute towards gas adsorption [16].

\section{CONCLUSION}

Activated carbon was successfully prepared from the agricultural waste carbonaceous source of Cocos nucifera (coconut) fibers using simple chemical and thermal modification process. The functional groups and the elemental composition of the prepared adsorbent were also determined by FT-IR and EDS analyses. It was proven from SEM analysis that the external surface of the prepared material after the chemical and thermal treatment had large pores when compared with the source material.

From the research carried out, it is concluded that the activated carbon produced from coconut
Table 3: Elemental composition of the adsorbent.

\begin{tabular}{|c|c|c|c|c|}
\hline \multicolumn{3}{|c|}{ Element } & \multirow{2}{*}{$\begin{array}{l}\text { Atomic } \\
\text { Conc. }\end{array}$} & \multirow{2}{*}{$\begin{array}{l}\text { Weight } \\
\text { Conc. }\end{array}$} \\
\hline No. & Symbol & Name & & \\
\hline 67 & $\mathrm{C}$ & Carbon & 89.10 & 79.66 \\
\hline 19 & $\mathrm{~K}$ & Potassium & 1.83 & 5.34 \\
\hline 8 & $\mathrm{O}$ & Oxygen & 4.26 & 5.07 \\
\hline 14 & $\mathrm{Si}$ & Silicon & 1.72 & 3.60 \\
\hline 26 & $\mathrm{Fe}$ & Iron & 0.54 & 2.24 \\
\hline 7 & $\mathrm{~N}$ & Nitrogen & 1.21 & 1.26 \\
\hline 13 & $\mathrm{Al}$ & Aluminium & 0.39 & 0.79 \\
\hline 12 & $\mathrm{Mg}$ & Magnesium & 0.29 & 0.52 \\
\hline 16 & $\mathrm{~S}$ & Sulfur & 0.21 & 0.50 \\
\hline 15 & $\mathrm{P}$ & Phosphorus & 0.22 & 0.50 \\
\hline 17 & $\mathrm{Cl}$ & Chlorine & 0.14 & 0.36 \\
\hline 11 & $\mathrm{Na}$ & Sodium & 0.09 & 0.16 \\
\hline
\end{tabular}

fibers would be useful and effective as an absorbent considering the large pores it had.

\section{References}

[1] M. Jasni, N. Abdullah, S. Abdullah, M. Abdul Razab, A. Mohamed Noor, M. Mohamed, N. Nik Yusuf, M. Mohd Amin, M. Mat Rasat, and M. Mohd Amin, "Preparation and characterization of activated carbon from cocos nucifera 1 . (coconut) shell and sugarcane bagasse," Int. J. Cur. Res. Eng. Sci. Tech., vol. 1, pp. 416-421, 2018.

[2] B. Pendyal, M. Johns, W. Marshall, M. Ahmenda, and R. Rao, "The effect of binders and agricultural byproducts on physical and chemical properties of granular activated carbons." Bioresource Technology, vol. 68, pp. 247-254, 1999.

[3] M. Tekker, O. Saltabas, and M. Imamoglu, "Adsorption of cobalt by activated carbon from rice hulls." Journal of Environmental Science Health A, vol. 32, no. 8, pp. 2077-2086, 1997.

[4] S. Pollard, G. Fowler, C. Sollars, and R. Perry, "Low cost adsorbents for waste and water treatment: A review." Science Total Environment, vol. 116, pp. 31-52, 1992.

[5] T. Muroyama, H. J., and S. Takemoto, "Production of activated carbon from bean-curd refuse by chemical activation with zncl 2 ," Tanso, vol. 166, pp. 34-39, 1995.

[6] J. Xia, N. Kiyoshi, S. Kagawa, and N. Wakao, "Production of activated carbon from bagasse (waste) of sugarcane grown in brazil." Journal of Chemical Engineering of Japan, vol. 13, pp. 987-990, 1998.

[7] E. Bernado, R. Egashira, and J. Kawaski, "Decolorization of molasses wastewater using activated carbon prepared from cane bagasse." Carbon, vol. 35, no. 9, pp. 1217-1221, 1998.

[8] T. Varila, D. Bergna, R. Lahti, H. Romar, T. Hu, and U. Lassi, "Activated carbon production from peat using zncl2: Characterization and applications." BioResources, vol. 12 , no. 4 , pp. 8078-8092, 2017.

[9] E. Jaguaribe, L. Medeiros, M. Barreto, and L. Araujo, "The performance of activated carbons from sugarcane bagasse, babassu, and coconut shells in removing redidual chlorine." Brazilian Journal of Chemical Engineering, vol. 22 , no. 1 , pp. 41-47, 2005.

[10] M. Smíšek and S. Cerný, Active Carbon - Manufacture, Properties and Applications. Amsterdan: Elsevier, 1967

[11] T. I., E. N., E. U.E., and C. O., "Waste to wealthvalue recovery from agrofood processing wastes using biotechnology: A review." British Biotechnology Journal, vol. 4, pp. 418-481, 2014.

[12] H. Jankowska, A. Swiatkowski, and J. Choma, Active Carbon. Ellis Horwood, 1991. 
[13] D. Nevskaia, A. Santianes, V. Muñoz, and A. GuerreroRuiz, "Interaction of aqueous solutions of phenol with commercial activated carbons: An adsorption and kinetic study." Carbon, vol. 37, p. 1065, 1999.

[14] J. Coates and R. Meyers, Interpretation of infrared spectra, a practical approach, in encyclopedia of analytical chemistry. Chichester: John Wiley \& Sons Ltd, 1991.

[15] J. Hanson and A. Bacher, "Infrared spectroscopy." Organic chemistry online ir page, 2002.

[16] F. Boudrahem, F. Aissani-Benissad, and H. Ait-Amar, "Batch sorption dynamics and equilibrium for the removal of lead ions from aqueous phase using activated carbon developed from coffee residue activated with zinc chloride." J. Environ. Manage., vol. 90, pp. 30313039, 2009. 